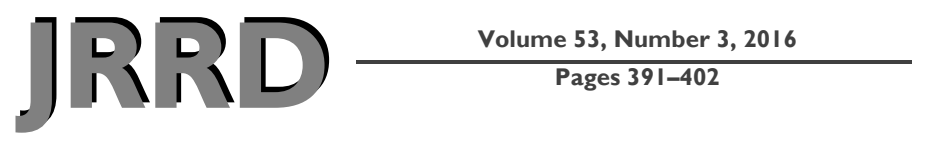

\title{
Health status and treatment-seeking stigma in older adults with trauma and posttraumatic stress disorder
}

\author{
Anica Pless Kaiser, PhD; ${ }^{1-2 *}$ Antonia Seligowski, MA; ${ }^{\mathbf{1}}$ Avron Spiro III, PhD; ${ }^{2-4}$ Mohit Chopra, MD $^{2,5}$ \\ ${ }^{1}$ Department of Veterans Affairs (VA) National Center for PTSD, VA Boston Healthcare System, Boston, MA; \\ ${ }^{2}$ Department of Psychiatry, Boston University School of Medicine, Boston, MA; ${ }^{3}$ Massachusetts Veterans Epidemiol- \\ ogy Research and Information Center, VA Boston Healthcare System, Boston, MA; ${ }^{4}$ Department of Epidemiology, Boston \\ University School of Public Health, Boston, MA; ${ }^{5}$ Department of Psychiatry, Harvard Medical School, Boston, MA
}

\begin{abstract}
This study compared health status across four trauma/posttraumatic stress disorder (PTSD) groups of older adults with depression, anxiety, and/or at-risk drinking who attended primary care appointments $(N=1,199$; mean age $=$ $73.5 \mathrm{yr}$ ), mostly at Department of Veterans Affairs hospitals. The trauma and PTSD categories were PTSD $(n=81)$, partial PTSD $(n=127)$, trauma only $(n=323)$, and no trauma $(n=$ 668). Physical and mental health-related quality of life (HQL), indices of social and economic impairment and stigma regarding treatment-seeking were compared among groups. Group differences were found for several indicators of functional impairment; the PTSD group had fewer close friends and higher treatment-seeking stigma beliefs related to having a disorder. Linear mixed modeling examined associations between trauma/PTSD group and HQL. After accounting for covariates, the trauma/PTSD groups differed across the Medical Outcome Study Short Form-36 scales and component scores (indicated by significant group by scale interaction). Differences among groups were confined to mental health measures; those with PTSD had worse HQL. Post hoc analyses examined the number of comorbid psychiatric diagnoses by trauma/PTSD group. Overall, findings indicate that mental HQL varies among older adults with trauma and PTSD and that although treatmentrelated stigma does not differ among groups, it does affect HQL.
\end{abstract}

Key words: aging, comorbidity, health-related quality of life, linear mixed modeling, mental health, physical health, posttraumatic stress disorder, stigma, trauma, treatment-seeking.

\section{INTRODUCTION}

Military service is often considered a hidden factor associated with aging with regards to effect on health and functioning [1]. In 2011, approximately 40.5 percent of the Veteran population was aged 65 yr or older [2]. A 2012 Institute of Medicine report revealed that almost one in five older adults has one or more mental health conditions, and those with posttraumatic stress disorder (PTSD) commonly have comorbid depressive or anxiety disorders and physical health problems [3].

Estimates of PTSD prevalence in adults aged $60 \mathrm{yr}$ and older range from 0.6 to 4.5 percent [4-5]. Among

Abbreviations: ANOVA = analysis of variance, GLM = generalized linear modeling, HQL = health-related quality of life, $\mathrm{LMM}=$ linear mixed modeling, $\mathrm{MCS}=$ mental component score, PCS = physical component score, PRISM-E = Primary Care Research in Substance Abuse and Mental Health for the Elderly, PTSD = posttraumatic stress disorder, SF-36 = Medical Outcome Study Short Form-36, VA = Department of Veterans Affairs.

*Address all correspondence to Anica Pless Kaiser, PhD; VA National Center for PTSD, VA Boston Healthcare System, 150 S. Huntington Ave (116-B2), Boston, MA 02130; 857-364-5309; fax: 857-364-4501.

Email: anica.plesskaiser@va.gov

http://dx.doi.org/10.1682/JRRD.2015.03.0039 
those seeking mental health treatment, estimates increase to 37 to 80 percent [6]. Many older adults may not meet all criteria for a PTSD diagnosis, but controversy exists regarding criteria for partial (or subclinical) PTSD. Some researchers define partial PTSD as meeting criterion B (re-experiencing) and at least one symptom from both criteria C (avoidance and numbing) and D (hyperarousal) [7], whereas others argue for inclusion of additional symptoms [8-9]. Estimates of the prevalence of subclinical PTSD among older adults ranges from 5.5 to 15 percent [5,10-12].

In addition to experiencing issues related to PTSD itself, symptoms of this disorder are associated with higher rates of stigma [13] as well as with other mental health problems such as depression, other anxiety disorders, and substance misuse [13-15]. Pietrzak et al. examined comorbidity of PTSD and partial PTSD in a nationally representative sample and found that both were associated with elevated levels of mood, anxiety, and substance use disorders [16]. An earlier study using the Primary Care Research in Substance Abuse and Mental Health for the Elderly (PRISM-E) cohort (the same dataset used in the current investigation) reported elevated comorbid anxiety and depressive disorders among older adults with PTSD or partial PTSD [17]. Given the rising number of older adults and the prevalence of PTSD symptoms, it is essential to understand clinical issues, such as health-related quality of life (HQL), functional impairment, and stigma, among those affected.

In addition to higher psychiatric comorbidity, people with PTSD symptoms report lower HQL [18]. In a sample of World War II and Korean war Veterans, Richardson et al. found that PTSD diagnosis was negatively correlated with mental health functional status and that physical and mental health functioning scores were lower than those of comparable individuals within the community [19]. Additionally, studies of Veterans in primary care have found that PTSD symptoms were related to poorer physical and mental health and worse social functioning [20-21]. Among male Veterans in the Veterans Health Study, those with PTSD scored lower (indicating worse functioning) on all eight Medical Outcome Study Short Form-36 (SF-36) scales than did Veterans with depression or neither disorder, with larger differences found on the mental health scales [22].

In addition to lower HQL, PTSD symptoms are related to problems in occupational and social functioning. MacDonald et al. found that the presence of PTSD symptoms had a negative effect on interpersonal relationships among Veterans [23]. Decreased ability to maintain employment has also been linked to PTSD symptoms [20].

Stigma can affect the level of impairment associated with symptoms of PTSD. Mental health stigma can lead individuals to feel ashamed, think of themselves as weak, and lose self-respect-all of which can increase distress and social problems and decrease willingness to seek treatment [24]. Stigma related to mental health diagnoses and treatment is particularly salient within the older adult population and has been associated with decreased satisfaction with mental health treatment [25-26].

The purpose of the current study was to examine differences in HQL, functional impairment, and treatmentseeking stigma among four groups: PTSD, partial PTSD, trauma only, and no trauma. To our knowledge, this is the first study to examine HQL and indices of functioning by trauma/PTSD group within an elderly sample. We also add to the literature by examining stigma beliefs related to treatment-seeking in older adult primary care patients. We hypothesized that with increasing PTSD symptoms (e.g., trauma only vs partial PTSD vs PTSD) there would be increased endorsement of treatment-seeking stigma and functional impairment. We also predicted that trauma/PTSD group status would be associated with mental and physical HQL, such that the PTSD group would display worse functioning across domains.

\section{METHODS}

\section{Design}

We used baseline assessments from a large multisite trial, the PRISM-E study, that compared two models of mental health care delivery for older primary care patients (data were collected 2000-2002). Potential participants were assessed in person at nine primary care clinics (six Department of Veterans Affairs [VA] and three non-VA) for depressive disorders, anxiety disorders, and at-risk drinking [27]. Adults diagnosed with psychotic disorders or manic or hypomanic episodes were excluded, as were those who were in active mental health treatment [28].

\section{Participants}

Participants were 1,199 primary care patients aged $65 \mathrm{yr}$ or older (59\% of enrolled sample; mean \pm standard 
deviation: $73.5 \pm 6.0 \mathrm{yr}$ ) who were assessed for trauma history and PTSD symptoms. The majority of the sample was male (87\%), did not have a college degree (87\%), described themselves as Caucasian (59\%), and were VA patients (82\%). About half (49\%) were married. Consistent with previous reports from these data $[17,28]$, participants were categorized into four groups. A majority $(n=$ $668 ; 56 \%$ ) reported never experiencing a traumatic event and were categorized into the no trauma group. Those who indicated having traumatic experience(s) but denied having PTSD symptoms within the past month were categorized into the trauma only group $(n=323 ; 27 \%)$. Participants with some PTSD symptoms but who did not meet full criteria were categorized into the partial PTSD group ( $n=127 ; 11 \%)$. Respondents who met full criteria for PTSD $(n=81 ; 7 \%)$ comprised the PTSD group (Table 1).

\section{Measures}

Demographic characteristics assessed included age (in years) and sex. Site of assessment was indexed as $0=$ non-VA and $1=$ VA.

The Mini International Neuropsychiatric Inventory is a structured clinical interview containing modules that assess psychiatric diagnoses according to Diagnostic and Statistical Manual of Mental Disorders-4th Edition-Text Revision criteria [29]. Questions have a "yes" or "no" response format. Besides PTSD, depressive and other anxiety disorders were assessed. To assess for PTSD, participants were asked whether they had experienced a traumatic event, and examples of potentially traumatic events were provided. If the response was positive, the presence of symptoms from each PTSD symptom cluster and interference and/or distress were assessed. If the threshold number of symptoms for a symptom cluster was not met, further clusters were not assessed.

At-risk drinking was defined as either (1) $\geq 14$ drinks/ wk for men ( $\geq 12$ drinks/wk for women) and/or (2) binge drinking ( $>6$ drinks on any day) during the previous 3 mo. Participants were not assessed for alcohol abuse or dependence.

The number of comorbid diagnoses was indexed for each participant. This variable was created by summing the number of diagnoses within categories of major depressive disorder, other depression, panic, generalized anxiety disorder, and at-risk drinking for each participant (possible range: 1-5).
The SF-36, a 36-item scale, assesses the effects of physical and mental health on well-being and is often used to assess HQL [30]. The SF-36 comprises eight scales (physical functioning, role physical, bodily pain, general health, vitality, social functioning, role emotional, and mental health), each with a possible range of 0 (least favorable) to 100 (most favorable). Scores from these scales are used to compute two component scores: physical component score (PCS) and mental component score (MCS), which are standardized $t$-scores (50 \pm 10 ) [31].

Several self-report indices were used to assess functional impairment. Work status was indexed as $1=$ not employed, 2 = employed part-time, and $3=$ employed full-time. Volunteer status was indexed as $0=$ does not volunteer and 1 = does volunteer. Participants were asked whether they were eligible for VA benefits; eligible Veterans reported the percentage of service connection received. Positive responses were categorized as $<50$ percent, 50 to 99 percent, and 100 percent. Financial status was categorized as $0=$ can't make ends meet, $1=$ have just enough, and 2 = comfortable.

Interpersonal functioning was evaluated with several variables. Number of close friends and relatives was assessed with separate questions, each with response options ranging from $1=$ none to $5=10$ or more. Participants were asked whether they belonged to any social groups (e.g., church, union), and this item was coded as $0=$ does not belong to group(s) and 1 = belongs to group(s).

Stigma beliefs related to mental health treatmentseeking were assessed with two questions. The questions used in the existing data set depart from the typical definition of stigma related to mental health problems. Instead, the questions asked in the current study assess treatment-seeking stigma. Prior to being asked the treatment-seeking stigma questions, participants were oriented to think about whether they would feel stigmatized if they had a mental health and/or an alcohol use problem. Depending on the participants' answers, they were asked the following questions about treatment for a mental health problem, alcohol use problem, or mental health and alcohol use problem. Questions were, "Do you think people around you would think differently of you if you received mental health or alcohol abuse treatment?" (anticipated stigma about treatment-seeking) and "Would it be difficult for you to start mental health or alcohol abuse treatment if other people knew you were going to be in treatment?” (anticipated effect of treatment-seeking stigma). Anticipated stigma about treatment-seeking is 
JRRD, Volume 53, Number 3, 2016

Table 1.

Sample characteristics by trauma/posttraumatic stress disorder (PTSD) category $(N=1,199)$.

\begin{tabular}{|c|c|c|c|c|c|c|}
\hline Variable & $N$ & $\begin{array}{l}\text { No Trauma } \\
(n=668)\end{array}$ & $\begin{array}{l}\text { Trauma Only } \\
(n=323)\end{array}$ & $\begin{array}{c}\text { Partial PTSD } \\
(n=127)\end{array}$ & $\begin{array}{c}\text { PTSD } \\
(n=81)\end{array}$ & Omnibus Statistic \\
\hline$\overline{\text { Age, yr (mean } \pm \text { SD) }}$ & 1,199 & $73 \pm 6.1$ & $74 \pm 6.0$ & $74 \pm 5.4$ & $72 \pm 5.2$ & $F(3,1,198)=1.3$ \\
\hline Male (\%) & 1,185 & 82 & 95 & 91 & 83 & $\chi^{2}(3)=35.3^{*}$ \\
\hline Depression (\%) & 1,199 & 79 & 76 & 84 & 98 & $\chi^{2}(3)=20.8^{*}$ \\
\hline Anxiety (\%) & 1,199 & 18 & 27 & 38 & 52 & $\chi^{2}(3)=61.7^{*}$ \\
\hline At-Risk Drinking (\%) & 1,199 & 25 & 31 & 30 & 14 & $\chi^{2}(3)=11.4^{\dagger}$ \\
\hline Financial Status (\%) & 1,199 & & & & & $\chi^{2}(6)=37.7^{*}$ \\
\hline Can’t Make Ends Meet & & 26 & 16 & 24 & 42 & \\
\hline Have Just Enough & & 48 & 50 & 43 & 49 & \\
\hline Comfortable & & 26 & 34 & 33 & 9 & \\
\hline Work Status (\%) & 1,191 & & & & & $\chi^{2}(6)=8.4$ \\
\hline Not Working & & 89 & 84 & 83 & 93 & \\
\hline Part-Time & & 8 & 12 & 13 & 5 & \\
\hline Full-Time & & 3 & 3 & 4 & 2 & \\
\hline Volunteer (\%) & 1,192 & 12 & 21 & 25 & 11 & $\chi^{2}(3)=20.0^{*}$ \\
\hline Site (\%) & 1,199 & & & & & $\chi^{2}(3)=52.9^{*}$ \\
\hline Non-VA & & 24 & 7 & 11 & 30 & \\
\hline VA & & 76 & 93 & 89 & 70 & \\
\hline VA Benefits (\%) & 377 & & & & & $\chi^{2}(6)=6.0$ \\
\hline$<50 \%$ & & 19 & 22 & 29 & 21 & \\
\hline $50 \%-99 \%$ & & 5 & 5 & 5 & 7 & \\
\hline $100 \%$ & & 4 & 7 & 11 & 6 & \\
\hline $\begin{array}{l}\text { Anticipated Stigma About } \\
\text { Treatment-Seeking: } \\
\text { Very Difficult (\%) }\end{array}$ & 938 & 28 & 15 & 24 & 44 & $\chi^{2}(6)=37.8^{*}$ \\
\hline $\begin{array}{l}\text { Anticipated Effect of } \\
\text { Treatment-Seeking } \\
\text { Stigma: Very Difficult (\%) }\end{array}$ & 949 & 11 & 11 & 10 & 13 & $\chi^{2}(6)=1.0$ \\
\hline Social Group (\%) & 1,196 & 41 & 56 & 58 & 43 & $\chi^{2}(3)=26.1^{*}$ \\
\hline $\begin{array}{l}\text { Close Friends (mean } \pm \\
\text { SD) }\end{array}$ & 1,192 & $2.7 \pm 1.4$ & $2.9 \pm 1.4$ & $2.9 \pm 1.4$ & $2.4 \pm 1.4$ & $F(3,1,188)=4.9^{\mp}$ \\
\hline $\begin{array}{l}\text { Close Relatives (mean } \pm \\
\text { SD) }\end{array}$ & 1,181 & $3.1 \pm 1.3$ & $3.2 \pm 1.3$ & $3.0 \pm 1.4$ & $2.7 \pm 1.2$ & $F(3,1,177)=2.7$ \\
\hline \multicolumn{7}{|c|}{$\begin{array}{l}\text { Note: All means are unadjusted. For depression, anxiety, and at-risk drinking: } 0=\text { no diagnosis and } 1=\text { diagnosis. For VA benefits, percentages reflect proportion of } \\
\text { total group, not all of whom were service-connected. For social group, values refer to percentages of group who belonged to any social groups. } \\
F_{p}<0.001 . \\
t_{p}<0.05 \text {. } \\
f^{t} p<0.01 \text {. } \\
\text { SD = standard deviation, VA = Department of Veterans Affairs. }\end{array}$} \\
\hline
\end{tabular}

defined as the view that other people would think negatively about you if you were in treatment for a mental health or alcohol use problem. Anticipated effect of treatment-seeking stigma is defined as the extent to which feeling stigmatized about treatment (if other people knew you were going to be in treatment for a mental health or alcohol use problem) would make it difficult to engage in that treatment. Response options for each question were
$0=$ not at all, $1=$ not very, $2=$ somewhat, and $3=$ very much.

\section{Analyses}

Descriptive statistics for all study variables were examined and comparisons (using one-way analyses of variance [ANOVAs] or chi-square tests) were conducted by trauma/PTSD category. Linear mixed modeling 
(LMM) was used to compare measures (SF-36 scale scores and SF-36 component scores) by trauma/PTSD category. Separate analyses were conducted for SF-36 scale scores and SF-36 component scores. Sex; age; assessment site; and diagnosis of depression, anxiety, and at-risk drinking were included as covariates. Variables considered to have a potential effect on HQL were included in the initial models: functional variables (work status, volunteering, anticipated stigma about treatmentseeking, and anticipated effect of treatment-seeking stigma) and interpersonal variables (number of friends, number of relatives, and social group membership). Significant variables $(p<0.05)$ were kept in the final models (one for SF-36 scale scores and another for SF-36 component scores). Models tested a trauma/PTSD group by scale interaction to examine possible differences across scale or component scores by trauma/PTSD group simultaneously.

Post hoc analyses examined the number of comorbid diagnoses by trauma/PTSD group using ANOVA. Additionally, univariate generalized linear modeling (GLM) was used to examine the effects of trauma/PTSD group on mental HQL with number of comorbid diagnoses as a covariate.

\section{RESULTS}

\section{Descriptive Statistics}

Table 1 provides descriptive information for study variables and comparisons by trauma/PTSD category. Groups did not differ by age, work status, VA benefits received, anticipated effect of treatment-seeking stigma, or number of close relatives. The no trauma group had fewer members who volunteered, and the trauma only and partial PTSD groups had significantly more members who volunteered than the other groups. Regarding financial status, a higher percentage of PTSD group members (42\%) reported difficulty "making ends meet" than reported by other groups (16\%-26\%).

People in the PTSD and no trauma groups reported having fewer friends than those in the trauma only group. A higher proportion of people in the trauma only and partial PTSD groups reported belonging to at least one group compared with those in other groups. A higher percentage of the PTSD group (44\%) strongly believed that others would think differently about them if they received mental health treatment (anticipated stigma about treat- ment-seeking) compared with the partial PTSD (24\%), trauma only (15\%), and no trauma (28\%) groups. In contrast, the groups did not differ on anticipated effect of treatment-seeking stigma.

\section{Health Status Profiles}

\section{Medical Outcome Study Short Form-36 Scales}

The final LMM examining SF-36 scales indicated significant effects of anticipated effect of treatment-seeking stigma, number of friends, and the trauma/PTSD group by scale interaction, controlling for other anxiety and depressive disorders. Those with higher SF-36 scale scores (indicating better HQL) endorsed less anticipated effect of treatment-seeking stigma and reported having more close friends (Table 2). The trauma/PTSD group by scale interaction was explored with pairwise comparisons. The PTSD group had significantly lower scores (worse functioning) than each of the other groups on SF-36 scales of social functioning, role limitations due to emotional problems, and mental health (Figure 1). There were no significant group differences on the physical health scales (Table 3).

\section{Medical Outcome Study Short Form-36 Component Scores}

The final LMM conducted to examine SF-36 component scores indicated effects of work status, volunteering, anticipated effect of treatment-seeking stigma, and a significant trauma/PTSD group by component interaction, controlling for anxiety disorders, depressive disorders, and at-risk drinking. Those with higher component scores (better functioning) worked full-time, volunteered, and endorsed less anticipated effect of treatment-seeking stigma (Table 4). Pairwise comparisons examined the significant trauma/PTSD group by component interaction. For the MCS, the PTSD group had significantly lower scores than the other groups (Figure 2). There were no significant group differences for the PCS (Table 3).

\section{Post Hoc Analyses}

Although individual comorbid disorders were controlled for in the main analyses, we were also interested in investigating the role of number of comorbid diagnoses within trauma/PTSD groups. Results of a one-way ANOVA indicted a mean difference in the number of comorbid diagnoses by trauma/PTSD group $(F(3,1,195)=$ 20.09, $p<0.001)$. Post hoc comparisons revealed that 
JRRD, Volume 53, Number 3, 2016

Table 2.

Estimates and tests of fixed effects: Medical Outcome Study Short Form-36 scales by trauma/posttraumatic stress (PTSD) disorder category.

\begin{tabular}{|c|c|c|c|c|c|c|}
\hline Parameter & Estimate & SE & $d f$ & $F$ & t-Value & $95 \% \mathrm{CI}$ \\
\hline Intercept & 64.4 & 2.6 & - & - & - & - \\
\hline Depression Dx & -22.3 & 1.0 & 939 & - & $-21.2^{*}$ & -24.3 to -20.2 \\
\hline Anxiety Dx & -8.8 & 1.0 & 943 & - & $-9.1^{*}$ & -10.8 to -6.9 \\
\hline Not At All vs Extremely & 3.7 & 1.3 & 939 & - & $2.8^{\dagger}$ & 1.1 to 6.3 \\
\hline \multicolumn{7}{|l|}{ No. of Friends } \\
\hline 0 vs $\geq 10$ & -9.2 & 1.3 & 940 & - & -7.2 & -11.7 to -6.7 \\
\hline $1-2$ vs $\geq 10$ & -5.0 & 1.2 & 942 & - & -4.0 & -7.4 to -2.6 \\
\hline $3-5$ vs $\geq 10$ & -3.2 & 1.2 & 941 & - & -2.7 & -5.5 to 0.8 \\
\hline $6-9$ vs $\geq 10$ & 0.1 & 1.6 & 940 & - & 0.1 & -3.0 to 3.3 \\
\hline
\end{tabular}

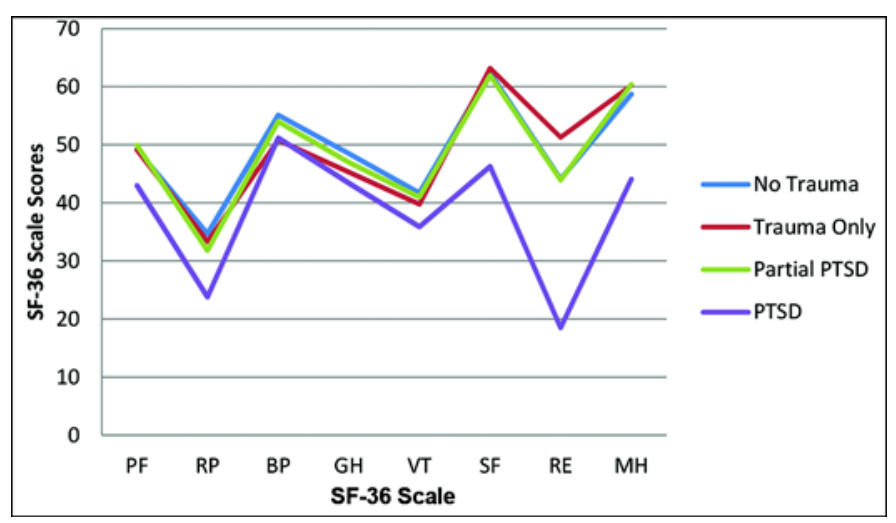

Figure 1.

Adjusted Medical Outcome Study Short Form-36 (SF-36) scale scores by trauma/posttraumatic stress disorder (PTSD) category. Possible range for all scales is 0 to 100 . BP = bodily pain, $\mathrm{GH}=$ general health, $\mathrm{MH}=$ mental health, $\mathrm{PF}=$ physical functioning, $\mathrm{RE}=$ role emotional, $\mathrm{RP}=$ role physical, $\mathrm{SF}=$ social functioning, VT = vitality.

although the partial PTSD and PTSD groups were not significantly different from each other, they were both significantly different from the other groups, such that participants in the partial PTSD and PTSD groups had more comorbid diagnoses. Additionally, number of comorbid diagnoses was correlated with mental HQL ( $r=$ $-0.33, p<0.001)$. However, after accounting for the effect of number of comorbid diagnoses in a univariate GLM examining mental HQL, trauma/PTSD group remained significant.

\section{DISCUSSION}

This study examined differences in mental and physical HQL and indices of functional impairment and treatment-seeking stigma among older primary care patients categorized into four trauma/PTSD groups. Results were generally consistent with the literature, suggesting that older adults with PTSD report lower mental HQL across multiple domains of functioning [16]. Differences among groups were found with regards to demographics, interpersonal functioning, functional impairment, and treatment-seeking stigma. Older primary care patients with PTSD are affected by treatment-seeking stigma and the consequences of poorer social and role functioning, evidenced by factors such as limited social relationships and financial strain.

Similar to findings within the general population [8], results from the current study indicate that older adults (and Veterans) with PTSD have more psychological, social, and financial problems, as well as greater treatment-seeking stigma beliefs, than those with fewer or no PTSD symptoms. Further, PTSD has an added negative influence on mental HQL, even after accounting for 
Table 3.

Adjusted Medical Outcome Study Short Form-36 scales and component scores by trauma/posttraumatic stress disorder (PTSD) category.

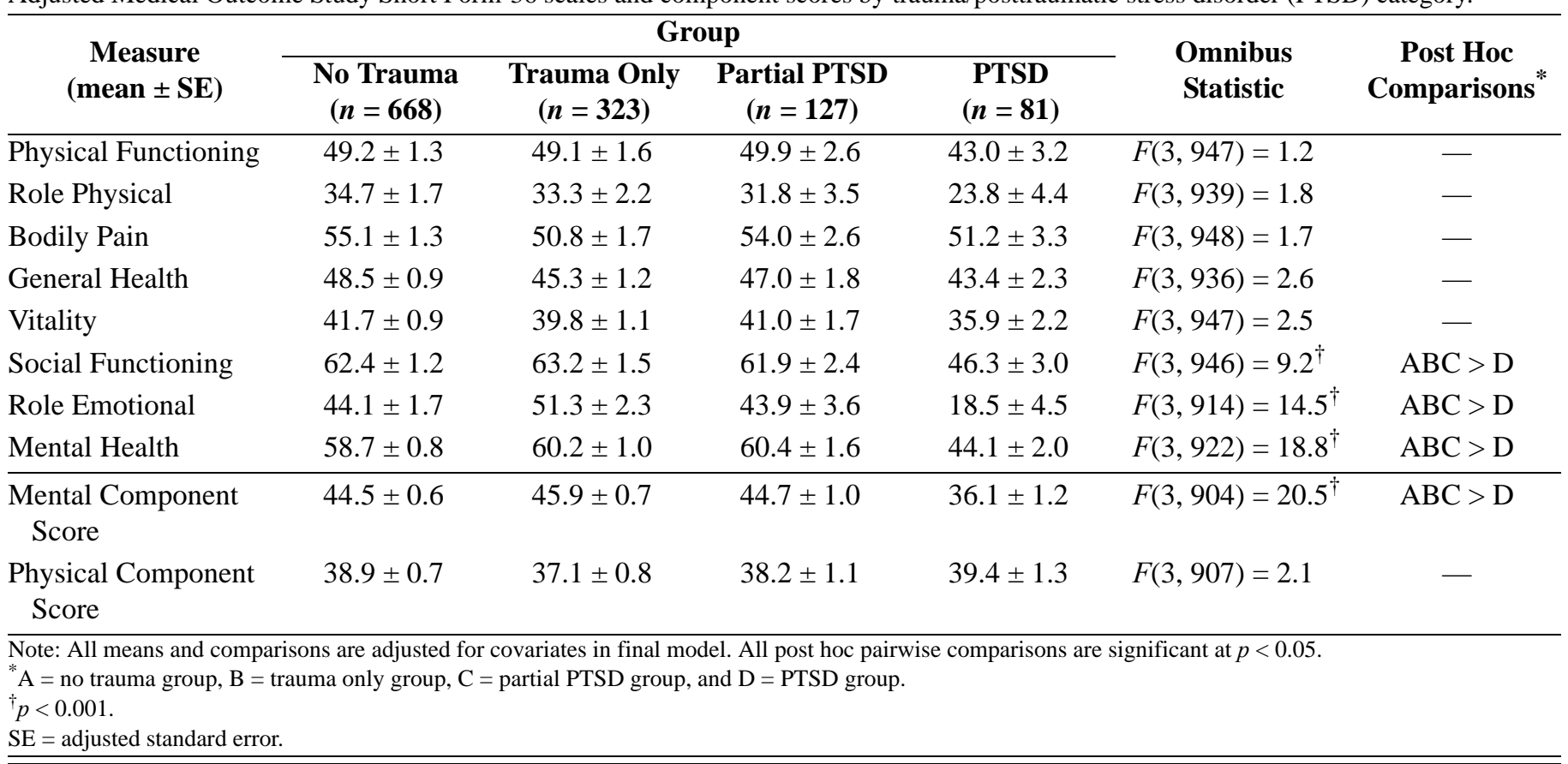

Table 4.

Estimates and tests of fixed effects: Medical Outcome Study Short Form-36 component scores by trauma/posttraumatic stress disorder (PTSD) category.

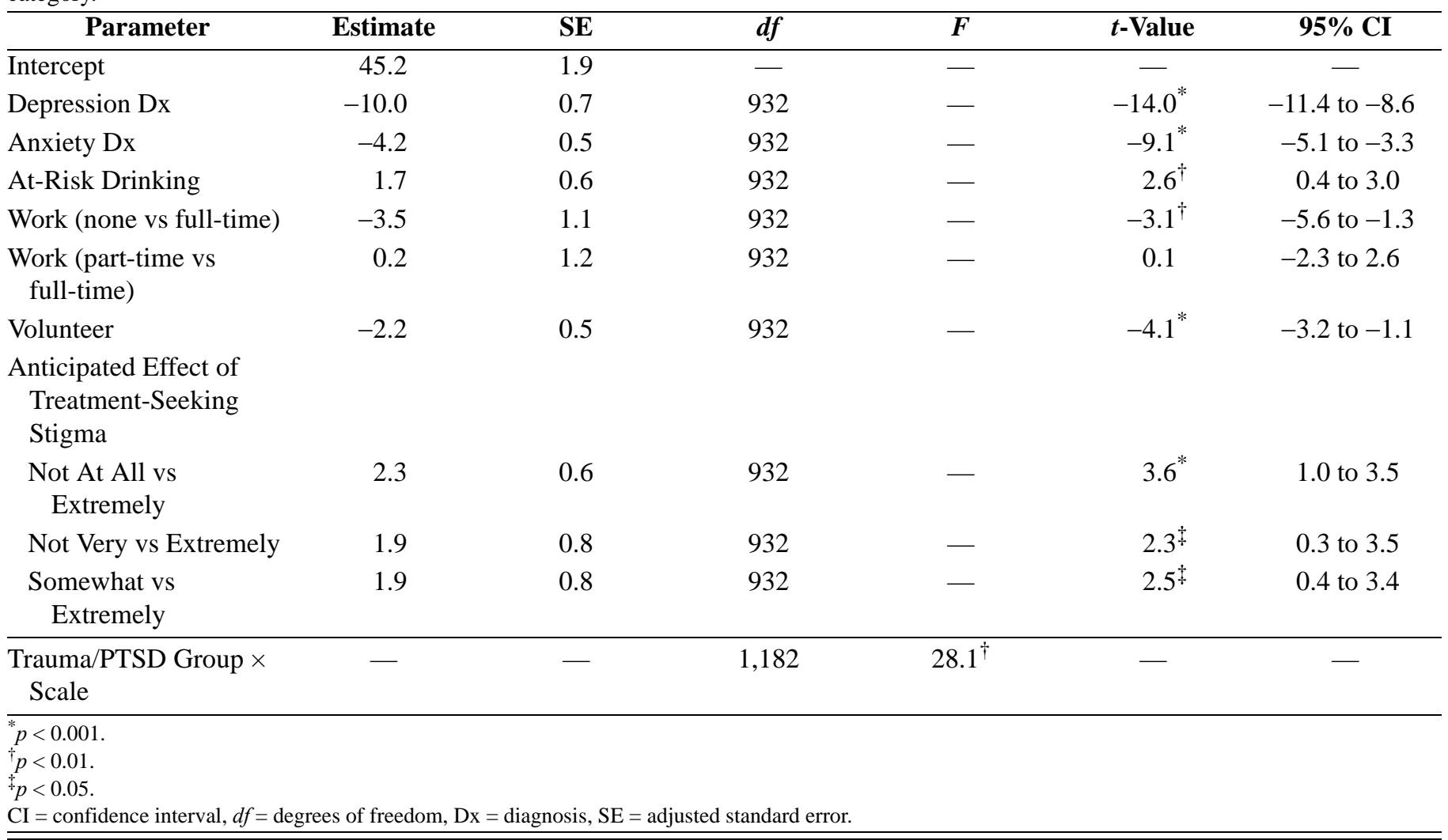




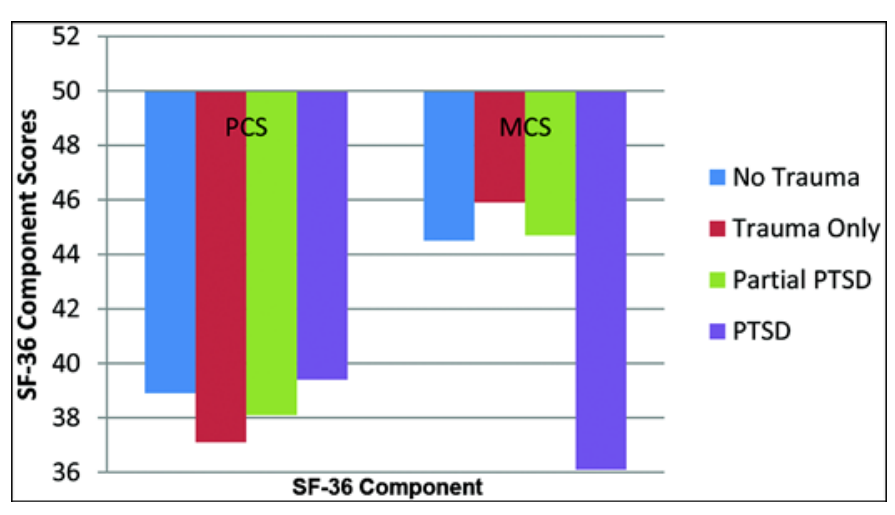

Figure 2.

Adjusted Medical Outcome Study Short-Form 36 (SF-36) component scores by trauma/posttraumatic stress disorder (PTSD) category. Mean \pm standard deviation: $50 \pm 10$. PCS = physical component score, MCS = mental component score.

comorbid mental health diagnoses. However, our hypothesis regarding a progressive decrease in mental and physical HQL with increased PTSD symptoms (e.g., differences between partial PTSD and PTSD groups) was not supported. Participants in the partial PTSD and PTSD groups had higher numbers of comorbid diagnoses than members of the other groups.

Older adults with PTSD had lower scores on the SF36 scales of social functioning, role limitations due to emotional problems, and mental health than members of the other groups. The PTSD group also demonstrated poorer mental health functioning based on the overall MCS. These findings are consistent with other studies finding worse mental health functioning among people with PTSD [19-20,22]. Additionally, members of the PTSD group were more likely to report financial difficulty and endorse more stigma beliefs associated with mental health treatment-seeking than members of the other groups.

The relationship between PTSD symptoms and interpersonal functioning was not straightforward. Older adults in the trauma only group reported having more close friends than adults in the no trauma and PTSD groups. Those in the no trauma and PTSD groups reported belonging to fewer social groups than those in the other groups. There are a number of possible explanations for these findings. Perhaps people who experience trauma seek out social support to a greater extent than those without trauma histories, but those with more severe symptoms avoid socializing in groups and thus don't have as many lasting friendships. Other possible explanations (e.g., biological responses to trauma, mechanisms related to resilience) may also shed light on these findings and provide opportunities for future research.

In contrast to the differences found by group, when indices of interpersonal functioning were included in the LMM models, only number of friends demonstrated a significant effect on the SF-36 scales. This effect indicated that, after accounting for other variables in the model, those with more friends had higher levels of HQL (better functioning) than those with fewer friends. Work status (working full-time) and volunteering were additional aspects of functioning that had independent positive effects on HQL. Several studies suggest that volunteering may provide benefits such as improved health and well-being for older adults [32-33], and social support and occupational findings are also consistent with the literature [20,34].

Another facet of functional impairment examined was stigma related to seeking mental health treatment. Older adults in the PTSD group endorsed more concern about what others would think of them if they received treatment. Despite this, the majority of each group asserted that they would not have difficulty starting treatment if others knew about it. When included in the LMM models, anticipated effect of treatment-seeking stigma was significantly associated with both SF-36 scales and component scores such that people with higher treatment-seeking stigma beliefs had lower HQL. One hypothesis is that, for participants with PTSD, their perceptions of what other people think of them had a more negative influence on their HQL than on their actions if they thought seeking treatment was important. These findings may be positive, because they suggest that older adults may be willing to seek treatment for mental health problems in spite of perceived treatment-seeking stigma, and that, as suggested by Gould et al., lowering stigma related to treatmentseeking may improve HQL [35].

Physical health functioning did not differ among the trauma/PTSD groups in the LMM models. This finding differs from studies demonstrating that older individuals with PTSD have worse physical health function and more physical health problems than those without PTSD [3637]. This difference could be related to selection biases affecting our sample. For example, it is possible that older individuals in poor physical health were unable to participate in this study because of disability, decreased mobility, or mortality. In addition, participants in the current 
study were older than in many other samples. It is also possible that in this sample, the effect of age on physical health was greater than the effect of PTSD.

One limitation of this study involves the manner in which the trauma/PTSD groups were created. First, the partial PTSD group (participants endorsed a trauma and symptoms but not enough to meet full diagnostic criteria) was created inclusively, which may have made the group overly heterogeneous. Second, all participants had comorbid depression, anxiety, or at-risk drinking diagnoses. However, it is rare to observe PTSD without comorbidities in the general population.

Treatment-seeking stigma was assessed with only two questions; a more detailed assessment of negative beliefs and barriers to care would help to further elucidate differences between groups and effect on HQL. The questions themselves were not optimal; the way in which they were phrased made it difficult to discern the meaning of the response, and follow-up questions that may have clarified the responses were not asked. For example, the question about whether people would think differently of the person if they received treatment does not allow for participants to indicate whether the effect was viewed as positive or negative. Prior to being asked this question, however, participants were prompted to think about whether they would feel stigmatized (negatively) if they had a mental health or alcohol use problem, so it is possible that they were primed to endorse the extent to which they felt negative stigma. Additionally, the question also lumps types of treatment together (e.g., mental health or alcohol abuse treatment), which makes it difficult to know which treatment the participant was referring to when responding to the question. Because this study was based on an existing data set, additional questions related to treatment-seeking stigma were not available. The limited nature of the questions about treatmentseeking stigma in the larger study was likely due to stigma not being a primary focus and concerns about participant burden.

An additional limitation of this study was the crosssectional nature of the data, which only provides a snapshot of PTSD symptoms and functioning. A particularly relevant limitation of this cross-sectional study is that prior treatment status is unknown. This may be an important factor that might help to explain group differences; for example, it is possible that participants in the trauma only and partial PTSD groups were more likely to have previously engaged in successful treatment and thus demonstrated better functioning at the time of the study. In future research, it will be important to assess treatment engagement, as well as the course and severity of symptoms, longitudinally.

\section{CONCLUSIONS}

The findings from this study expose very real areas of impairment, especially in mental HQL and treatmentseeking stigma experienced by older adults who have PTSD diagnoses, some of whom have experienced chronic PTSD symptoms throughout their lives. A positive observation from this study is that the anticipated effect of treatment-seeking stigma does not appear to affect these primary care patients' readiness to accept help for mental health conditions. These findings offer a real opportunity for intervention if other barriers to mental health treatment-seeking can also be overcome. The findings regarding greater number of friends and higher engagement in work and/or volunteer activities points to clear ways in which much-needed help can be delivered to older adults and Veterans who might have lived in silence for a long time.

\section{ACKNOWLEDGMENTS}

\section{Author Contributions:}

Study concept and design: A. Pless Kaiser, A. Spiro, M. Chopra. Acquisition of data: M. Chopra.

Analysis and interpretation of data: A. Pless Kaiser, A. Spiro, M. Chopra.

Drafting of manuscript: A. Pless Kaiser, A. Seligowski.

Critical revision of manuscript for important intellectual content:

A. Pless Kaiser, A. Spiro, M. Chopra, A. Seligowski.

Statistical analysis: A. Pless Kaiser.

Administrative, technical, or material support: A. Seligowski.

Financial Disclosures: The authors have declared that no competing interests exist.

Funding/Support: This material was based on work supported by the National Institute of Aging (grant R24-AG039343) and a VA Senior Research Career Scientist Award to Dr. Spiro from the VA Clinical Science Research and Development Service. The PRISM-E was funded jointly by the Substance Abuse and Mental Health Services Administration, the VA, and the Centers for Medicare and Medicaid Services. This work was supported with resources and the use of facilities at the VA Boston Healthcare System.

Additional Contributions: The authors express their appreciation for the contributions of their colleagues in the Stress, Health, and Aging Research Program, VA Boston Healthcare System. Ms. Seligowski is 
now with Northern Illinois University, DeKalb, Illinois, and Dr. Chopra is now with Brockton Multi Services Center, Boston, Massachusetts.

Institutional Review: The VA Boston Healthcare System Institutional Review board approved the current study. All research procedures were carried out after the approval of local institutional review boards, and written informed consent was obtained from all participants.

Participant Follow-up: The authors do not plan to inform participants of the publication of this study.

Disclaimer: The views expressed in this article are those of the authors and do not represent the VA.

\section{REFERENCES}

1. Spiro A, Schnurr PP, Aldwin CM. A life-span perspective on the effects of military service. J Geriatr Psychiatry. 1997;30(1):91-128.

2. Department of Veterans Affairs. Strategic plan refresh: Fiscal year (FY) 2011-2015. Washington (DC): Department of Veterans Affairs, 2010.

3. Committee on the Mental Health Workforce for Geriatric Populations, Board on Health Care Services, Institute of Medicine. The mental health and substance use workforce for older adults: In whose hands? Washington (DC): National Academies Press; 2012.

4. Acierno R, Ruggiero KJ, Galea S, Resnick HS, Koenen K, Roitzsch J, de Arellano M, Boyle J, Kilpatrick DG. Psychological sequelae resulting from the 2004 Florida hurricanes: Implications for postdisaster intervention. Am J Public Health. 2007;97(1 Suppl 1):S103-8. [PMID:17413067] http://dx.doi.org/10.2105/AJPH.2006.087007

5. Pietrzak RH, Goldstein RB, Southwick SM, Grant BF. Prevalence and axis I comorbidity of full and partial posttraumatic stress disorder in the United States: Results from wave 2 of the National Epidemiologic Survey on Alcohol and Related Conditions. J Anxiety Disord. 2011;25(3): 456-65. [PMID:21168991] http://dx.doi.org/10.1016/j.janxdis.2010.11.010

6. Blake DD, Keane TM, Wine PR, Mora C, Taylor KL, Lyons JA. Prevalence of PTSD symptoms in combat veterans seeking medical treatment. J Trauma Stress. 1990;3(1): 15-27. http://dx.doi.org/10.1002/jts.2490030103

7. American Psychiatric Association. Diagnostic and statistical manual of mental disorders. Revised. 4th ed. Washington (DC): American Psychiatric Association; 2000.

8. Cukor J, Wyka K, Jayasinghe N, Difede J. The nature and course of subthreshold PTSD. J Anxiety Disord. 2010; 24(8):918-23. [PMID:20655169] http://dx.doi.org/10.1016/j.janxdis.2010.06.017

9. Mylle J, Maes M. Partial posttraumatic stress disorder revisited. J Affect Disord. 2004;78(1):37-48.

\section{[PMID:14672795]}

http://dx.doi.org/10.1016/S0165-0327(02)00218-5

10. Glaesmer H, Gunzelmann T, Braehler E, Forstmeier S, Maercker A. Traumatic experiences and post-traumatic stress disorder among elderly Germans: Results of a representative population-based survey. Int Psychogeriatr. 2010; 22(4):661-70. [PMID:20353625] http://dx.doi.org/10.1017/S104161021000027X

11. Schnurr PP, Spiro A, Vielhauer MJ, Findler MN, Hamblen JL. Trauma in the lives of older men: Findings from the normative aging study. J Clin Geropsychol. 2002;8(3):17587. http://dx.doi.org/10.1023/A:1015992110544

12. van Zelst WH, de Beurs E, Beekman AT, Deeg DJ, van Dyck R. Prevalence and risk factors of posttraumatic stress disorder in older adults. Psychother Psychosom. 2003;72(6): 333-42. [PMID:14526136] http://dx.doi.org/10.1159/000073030

13. Ouimette P, Vogt D, Wade M, Tirone V, Greenbaum MA, Kimerling R, Laffaye C, Fitt JE, Rosen CS. Perceived barriers to care among Veterans Health Administration patients with posttraumatic stress disorder. Psychol Serv. 2011;8(3):212-23. http://dx.doi.org/10.1037/a0024360

14. Averill PM, Beck JG. Posttraumatic stress disorder in older adults: A conceptual review. J Anxiety Disord. 2000; 14(2):133-56. [PMID:10864382]

http://dx.doi.org/10.1016/S0887-6185(99)00045-6

15. Brady KT, Killeen TK, Brewerton T, Lucerini S. Comorbidity of psychiatric disorders and posttraumatic stress disorder. J Clin Psychiatry. 2000;61(7 Suppl 7):22-32. [PMID:10795606]

16. Pietrzak RH, Goldstein RB, Southwick SM, Grant BF. Psychiatric comorbidity of full and partial posttraumatic stress disorder among older adults in the United States: Results from wave 2 of the National Epidemiologic Survey on Alcohol and Related Conditions. Am J Geriatr Psychiatry. 2012;20(5):380-90. [PMID:22522959] http://dx.doi.org/10.1097/JGP.0b013e31820d92e7

17. Chopra MP, Zhang H, Pless Kaiser A, Moye JA, Llorente $\mathrm{MD}$, Oslin DW, Spiro A 3rd. PTSD is a chronic, fluctuating disorder affecting the mental quality of life in older adults. Am J Geriatr Psychiatry. 2014;22(1):86-97. [PMID:24314889] http://dx.doi.org/10.1016/j.jagp.2013.01.064

18. Rapaport MH, Clary C, Fayyad R, Endicott J. Quality-oflife impairment in depressive and anxiety disorders. Am J Psychiatry. 2005;162(6):1171-78. [PMID:15930066] http://dx.doi.org/10.1176/appi.ajp.162.6.1171

19. Richardson JD, Long ME, Pedlar D, Elhai JD. Posttraumatic stress disorder and health-related quality of life in pension-seeking Canadian World War II and Korean War veterans. J Clin Psychiatry. 2010;71(8):1099-1101. 


\section{[PMID:20797384]}

http://dx.doi.org/10.4088/JCP.09105920blu

20. Magruder KM, Frueh BC, Knapp RG, Johnson MR, Vaughan JA 3rd, Carson TC, Powell DA, Hebert R. PTSD symptoms, demographic characteristics, and functional status among veterans treated in VA primary care clinics. J Trauma Stress. 2004;17(4):293-301. [PMID:15462536] http://dx.doi.org/10.1023/B:JOTS.0000038477.47249.c8

21. Magruder KM, Frueh BC, Knapp RG, Davis L, Hamner MB, Martin RH, Gold PB, Arana GW. Prevalence of posttraumatic stress disorder in Veterans Affairs primary care clinics. Gen Hosp Psychiatry. 2005;27(3):169-79. [PMID:15882763] http://dx.doi.org/10.1016/j.genhosppsych.2004.11.001

22. Spiro A 3rd, Hankin CS, Mansell D, Kazis LE. Posttraumatic stress disorder and health status: The veterans health study. J Ambul Care Manage. 2006;29(1):71-86. [PMID:16340621] http://dx.doi.org/10.1097/00004479-200601000-00008

23. MacDonald C, Chamberlain K, Long N, Flett R. Posttraumatic stress disorder and interpersonal functioning in Vietnam War veterans: A mediational model. J Trauma Stress. 1999;12(4):701-7. [PMID:10646188] http://dx.doi.org/10.1023/A:1024729520686

24. Corrigan P. How stigma interferes with mental health care. Am Psychol. 2004;59(7):614-25. [PMID:15491256] http://dx.doi.org/10.1037/0003-066X.59.7.614

25. Chen H, Coakley EH, Cheal K, Maxwell J, Costantino G, Krahn DD, Malgady RG, Durai UN, Quijano LM, Zaman S, Miller CJ, Ware JH, Chung H, Aoyama C, Van Stone WW, Levkoff SE. Satisfaction with mental health services in older primary care patients. Am J Geriatr Psychiatry. 2006;14(4):371-79. [PMID:16582046] http://dx.doi.org/10.1097/01.JGP.0000196632.65375.b9

26. Segal DL, Coolidge FL, Mincic MS, O’Riley A. Beliefs about mental illness and willingness to seek help: A crosssectional study. Aging Ment Health. 2005;9(4):363-67. [PMID:16019293]

27. Levkoff SE, Chen H, Coakley E, Herr EC, Oslin DW, Katz I, Bartels SJ, Maxwell J, Olsen E, Miles KM, Constantino G, Ware JH. Design and sample characteristics of the PRISM-E multisite randomized trial to improve behavioral health care for the elderly. J Aging Health. 2004;16(1):3-27. [PMID:14979308] http://dx.doi.org/10.1177/0898264303260390

28. Durai UN, Chopra MP, Coakley E, Llorente MD, Kirchner JE, Cook JM, Levkoff SE. Exposure to trauma and posttraumatic stress disorder symptoms in older veterans attending primary care: Comorbid conditions and self-rated health status. J Am Geriatr Soc. 2011;59(6):1087-92.

[PMID:21649614]

http://dx.doi.org/10.1111/j.1532-5415.2011.03407.x
29. Sheehan DV, Lecrubier Y, Sheehan KH, Amorim P, Janavs J, Weiller E, Hergueta T, Baker R, Dunbar GC. The MiniInternational Neuropsychiatric Interview (M.I.N.I.): The development and validation of a structured diagnostic psychiatric interview for DSM-IV and ICD-10. J Clin Psychiatry. 1998;59(20 Suppl 20):22-33, quiz 34-57.

[PMID:9881538]

30. McHorney CA, Ware JE Jr, Lu JF, Sherbourne CD. The MOS 36-item Short-Form Health Survey (SF-36): III. Tests of data quality, scaling assumptions, and reliability across diverse patient groups. Med Care. 1994;32(1):40-66.

[PMID:8277801]

http://dx.doi.org/10.1097/00005650-199401000-00004

31. Ware JE, Kosinski M, Dewey JE. How to score version two of the SF-36 Health Survey. Lincoln (RI): Quality Metric Inc; 2000.

32. Gottlieb BH, Gillespie AA. Volunteerism, health, and civic engagement among older adults. Can J Aging. 2008;27(4): 399-406. [PMID:19416800] http://dx.doi.org/10.3138/cja.27.4.399

33. Wheeler JA, Gorey KM, Greenblatt B. The beneficial effects of volunteering for older volunteers and the people they serve: A meta-analysis. Int J Aging Hum Dev. 1998; 47(1):69-79. [PMID:9718488] http://dx.doi.org/10.2190/VUMP-XCMF-FQYU-V0JH

34. Brewin CR, Andrews B, Valentine JD. Meta-analysis of risk factors for posttraumatic stress disorder in traumaexposed adults. J Consult Clin Psychol. 2000;68(5):748-66. [PMID:11068961] http://dx.doi.org/10.1037/0022-006X.68.5.748

35. Gould M, Greenberg N, Hetherton J. Stigma and the military: Evaluation of a PTSD psychoeducational program. J Trauma Stress. 2007;20(4):505-15. [PMID:17721966] http://dx.doi.org/10.1002/jts.20233

36. Hall KS, Beckham JC, Bosworth HB, Sloane R, Pieper CF, Morey MC. PTSD is negatively associated with physical performance and physical function in older overweight military Veterans. J Rehabil Res Dev. 2014;51(2):285-95. [PMID:24933726]

http://dx.doi.org/10.1682/JRRD.2013.04.0091

37. Pietrzak RH, Goldstein RB, Southwick SM, Grant BF. Physical health conditions associated with posttraumatic stress disorder in U.S. older adults: Results from wave 2 of the National Epidemiologic Survey on Alcohol and Related Conditions. J Am Geriatr Soc. 2012;60(2):296-303. [PMID:22283516] http://dx.doi.org/10.1111/j.1532-5415.2011.03788.x

Submitted for publication March 5, 2015. Accepted in revised form August 3, 2015. 
JRRD, Volume 53, Number 3, 2016

This article and any supplementary material should be cited as follows:

Pless Kaiser A, Seligowski A, Spiro A 3rd, Chopra M. Health status and treatment-seeking stigma in older adults with trauma and posttraumatic stress disorder. J Rehabil Res Dev. 2016;53(3):391-402.

http://dx.doi.org/10.1682/JRRD.2015.03.0039
ORCID: Anica Pless Kaiser, PhD: 0000-0002-48030191; Avron Spiro III, PhD: 0000-0003-4080-8621; Mohit Chopra, MD: 0000-0002-9208-7224

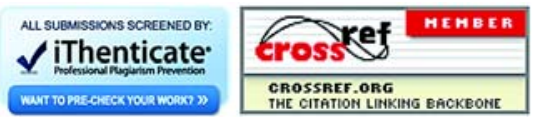

